TEKNIK, 42 (3), 2021, 260-272

\title{
Analisis Kematangan Batuan Induk Hidrokarbon di Formasi Naintupo, Sub-Cekungan Tarakan, Provinsi Kalimantan Utara
}

\author{
FX Anjar Tri Laksono ${ }^{1 *}$, Fendy Kusdiantoro² ${ }^{2}$ János Kovács ${ }^{3}$, Widhiatmoko Herry Purnomo ${ }^{4}$ \\ ${ }^{I}$ Departemen Teknik Geologi Fakultas Teknik, Universitas Jenderal Soedirman, \\ Jl. Mayjen Sungkono KM 5, Blater, Kalimanah, Purbalingga, Indonesia 53371 \\ ${ }^{2}$ Divisi Eksplorasi, Medco E\&P Indonesia \\ The Energy $53^{\text {rd }}$ Fl.SCBD Lot 11 A Jl. Jend. Sudirman, Kav. 52-53 Jakarta, Indonesia 12190 \\ ${ }_{1,3}$ Department of Geology and Meteorology, Faculty of Sciences, University of Pecs \\ Ifjúság str. 6, Pécs, Hongaria 7624 \\ ${ }^{4}$ Departemen Teknik Elektro, Fakultas Teknik, Universitas Jenderal Soedirman, \\ Jl. Mayjen Sungkono KM 5, Blater, Kalimanah, Purbalingga, Indonesia 53371
}

\begin{abstract}
Abstrak
Sub-Cekungan Tarakan yang terletak di Provinsi Kalimantan Utara diperkirakan memiliki potensi hidrokarbon sekitar dua miliar barel oil equivalent (BOE). Tujuan dari penelitian ini adalah menganalisis kematangan batuan induk dan potensi hidrokarbon di Formasi Naintupo, Sub-Cekungan Tarakan. Metode yang digunakan dalam kajian ini adalah analisis Total Organic Carbon (TOC), Vitrinite Reflectance (Ro), Hydrogen Index (HI), Tmax, Potential Yield (PY), S1, Oxygen Index (OI), dan Oil Production Index (OPI). Hasil kajian ini adalah Formasi Naintupo merupakan batuan induk efektif menghasilkan hidrokarbon dengan nilai TOC antara 1,02-5,92 wt.\%, HI 52-115 mgHC/gr TOC, Ro 0,62\%-1,84\%, Tmax $436^{\circ} \mathrm{C}-468^{\circ} \mathrm{C}$, S1 0,17-0,32, dan OPI sebesar 0,15-0,4. Jenis hidrokarbon dengan potensi terbesar adalah gas bumi. Potensi gas bumi terbesar berada di Sumur South Sembakung-1, Tanjung Bimau-1, Sesayap E-1, dan Tanjung Kramat-1. Hasil analisis menunjukkan bahwa Formasi Naintupo berpotensi menghasilkan gas bumi di Sub-Cekungan Tarakan.
\end{abstract}

Kata kunci: TOC;Ro; formasi Naintupo; hidrokarbon; sub-cekungan Tarakan

\begin{abstract}
[Title: The Maturity Analysis of Hydrocarbon Source Rock in the Naintupo Formation, Tarakan SubBasin, North Kalimantan Province] The Tarakan Sub-Basin, located in North Kalimantan Province, is estimated to have the hydrocarbon potential of around two billion barrels of oil equivalent (BOE). This study aims to analyze the maturity of the source rock and the hydrocarbon potential in the Naintupo Formation, Tarakan Sub-Basin. The method used in this study is the analysis of Total Organic Carbon (TOC), Vitrinite reflectance (Ro), Hydrogen Index (HI), Tmax, Potential Yield (PY), S1, Oxygen Index $(\mathrm{OI})$, and Oil Production Index (OPI). This research shows that the Naintupo Formation is an effective source rock with TOC between 1.02-5.92 wt.\%, HI 52-115 mg HC/gr TOC, Ro 0.62\% -1.84\%, Tmax $436 \circ \mathrm{C}-4680 \mathrm{C}$, S1 0.17-0.32, and OPI 0.15-0.4. The type of hydrocarbon with the greatest potential is natural gas. The largest natural gas potential is in the South Sembakung-1, Tanjung Bimau-1, Sesayap E1, and Tanjung Kramat-1 Wells. This study concludes that the Naintupo Formation has the potential to produce the natural gas in the Tarakan Sub-Basin.
\end{abstract}

Keywords: TOC; Ro; Naintupo formation; hydrocarbon; Tarakan Sub-Basin

\footnotetext{
${ }^{*}$ Penulis Korespondensi.

E-mail: anjar.trilaksono@unsoed.ac.id
}

\section{Pendahuluan}

Sub-Cekungan Tarakan di Kalimantan Utara diperkirakan memiliki potensi hidrokarbon sebesar dua miliar barrel of oil equivalent (BOE) tetapi potensi 


\section{TEKNIK, 42 (3), 2021, 261}

tersebut belum dimanfaatkan secara maksimal (Hidayati, 2018). Di Sub-Cekungan Tarakan pernah terdapat eksploitasi minyak dan gas bumi yang cukup besar, tetapi usaha eksplorasi kembali untuk menemukan sumbersumber migas baru di Sub-Cekungan tersebut hampir tidak pernah dilakukan. Eksplorasi migas di SubCekungan Tarakan sangat diperlukan untuk mencari sumber-sumber minyak dan gas baru, sehingga dapat menambah kapasitas produksi migas di Tarakan (Widjaja \& Noeradi, 2016).

Oleh sebab itu, tujuan penelitian ini adalah menganalisis kematangan batuan induk dan potensi hidrokarbon di Formasi Naintupo, Sub-Cekungan Tarakan. Analisis kematangan batuan induk yang sering dilakukan dalam kegiatan eksplorasi hidrokarbon meliputi Total Organic Carbon (TOC), Ro (Vitrinite Reflectance), dan REP (Rock Eval Pyrolisis) (Al-Areeq, 2018). Ketiga analisis tersebut penting karena informasi mengenai konsentrasi material organik, kematangan material organik, dan tipe material organik sangat diperlukan untuk mengetahui besarnya potensi dan jenis hidrokarbon yang dapat dihasilkan (Curiale, 2017; Nainggolan dkk., 2018). Ketepatan dalam melakukan analisis kematangan batuan induk, nantinya akan berpengaruh terhadap penentuan akumulasi hidrokarbon terbesar pada subcekungan tersebut (Laksono dkk., 2021; Xue dkk., 2019).

Lokasi penelitian terletak di Blok Simenggaris, Sub-Cekungan Tarakan, Kota Tarakan, Provinsi Kalimantan Utara pada 11 sumur eksplorasi minyak dan gas bumi yaitu Sumur Tanjung Tiram-1, Bangkudulis-1, Pulau Fanny-1, Sesayap E-1, Pidawan-1, Tanjung Bimau1, Tanjung Kramat-1, South Sembakung-1, Sembakung2, Sebuku-1, dan Daino-1 (Gambar 1). Studi tentang kematangan batuan induk hidrokarbon pernah dilakukan oleh Xiaoa dkk. (2019) yang menyatakan bahwa Nilai TOC untuk pembentukan minyak bumi antara $0,6 \%$ $0,9 \%$. Jika di atas $0,9 \%$ gas lebih dominan terbentuk, jika dibawah $0,6 \%$ belum terbentuk senyawa kompleks hidrokarbon. Berdasarkan integrasi antara peta struktur kedalaman dengan peta isopach terdapat dua lokasi yang berpotensi migas yang semuanya berada di lepas pantai tenggara Pulau Tarakan dengan jebakan berupa struktur antiklin yang dikontrol oleh sesar (Heriyanto, 2018; Sukanta, 2018). Hasil kajian tersebut mendukung kesimpulan penelitian yang pernah dilakukan oleh (Husein, 2017; Lentini, 2018) yang menyatakan bahwa kemungkinan terdapat potensi migas yang cukup besar di lepas pantai Pulau Tarakan. Penelitian sebelumnya hanya berfokus pada daerah onshore yang memang bukan hal baru. Selama ini produksi minyak dan gas di Tarakan berpusat di sekitar delta. Menurut Ronoatmojo \& Burhannudinnur (2018), Formasi Tabul tersusun atas batulempung, batulanau, dan batupasir yang diendapkan di lingkungan transisi selama Akhir Miosen.

Selama ini penelitian mengenai Sub-Cekungan Tarakan hanya fokus pada pencarian reservoir utama dan pengembangannya ke arah lepas pantai. Akan tetapi, studi batuan induk untuk menentukan formasi batuan efektif dan jenis hidrokarbon yang paling potensial dengan menggunakan data geokimia seperti TOC, Ro, dan REP belum pernah dilakukan. Jika selama ini Formasi Tabul menjadi reservoir utama di Sub-Cekungan Tarakan, maka ada kemungkinan Formasi Naintupo yang berumur lebih tua dapat menjadi batuan induknya. Hal tersebut menjadi celah penelitian yang perlu dilakukan kajian lebih lanjut karena memiliki implikasi terhadap pengembangan eksplorasi hidrokarbon Cekungan Tarakan.

\section{Bahan dan Metode}

Dalam penelitian ini dilakukan analisis Total Organic Carbon (TOC), Vitrinite Reflectance (Ro), Hydrogen Index (HI), Tmax, Potential Yield (PY), Oil Production Index (OPI), Oxygen Index, dan S1 Formasi Naintupo di Sumur Tanjung Tiram-1, Bangkudulis-1,

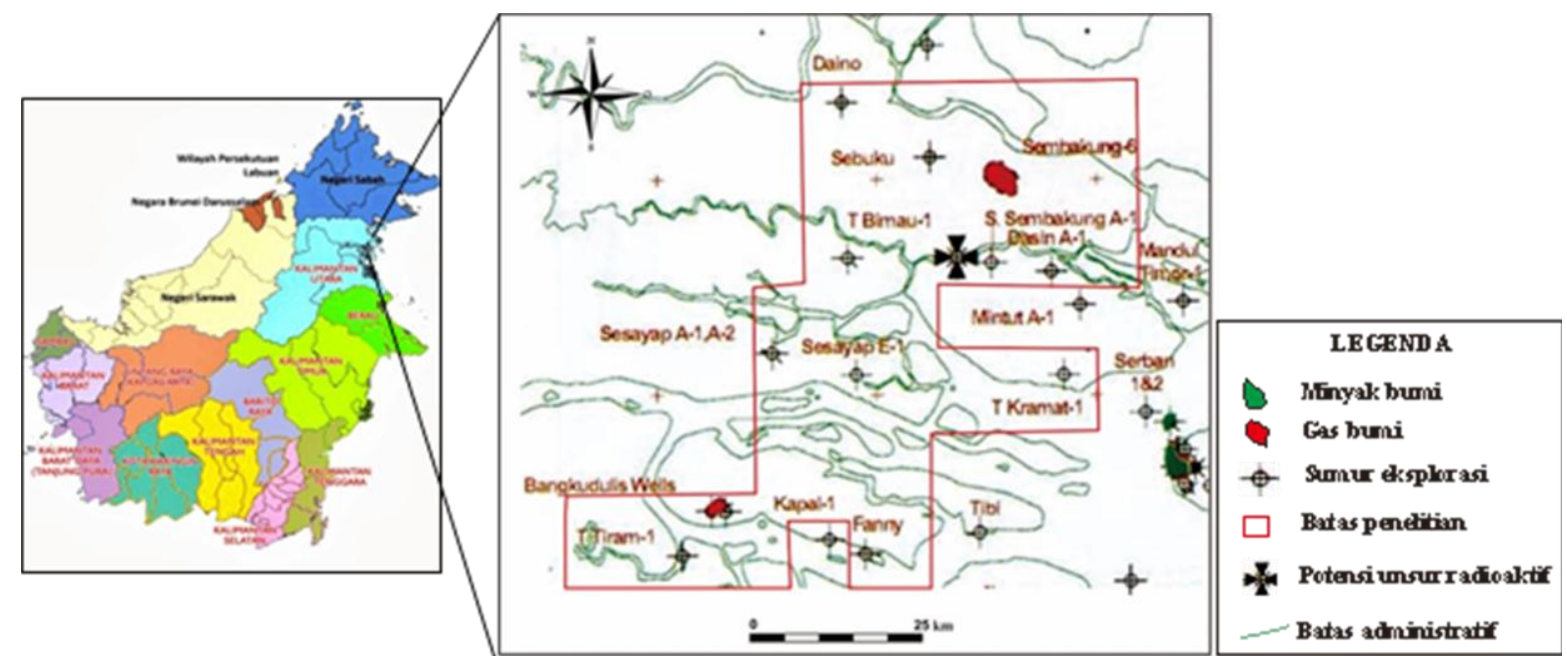

Gambar 1 Daerah penelitian Sub-Cekungan Tarakan, Kota Tarakan, Provinsi Kalimantan Utara (Zetra dkk., 2019).

doi: 10.14710/teknik.v42i3.35821

Copyright @ 2021, TEKNIK, p-ISSN: 0852-1697, e-ISSN: 240-9919 


\section{TEKNIK, 42 (3), 2021, 262}

Sesayap E-1, Pulau Fanny-1, Tanjung Kramat-1, Tanjung Bimau-1, Pidawan-1, South Sembakung-1, Sembakung-2, Sebuku-1, dan Daino-1. Analisis terhadap data tersebut akan memberikan informasi mengenai formasi batuan dan kedalaman lapisan batuan yang dapat menjadi batuan induk efektif hidrokarbon dan jenis hidrokarbon yang dihasilkan (Abdullah dkk., 2017; Chen dkk., 2017).

TOC merupakan berat rata-rata material organik dalam 100 gram batuan (Laksono dkk., 2020; Spacapan dkk., 2018). Menurut Walters (2017) batuan induk dapat dikelompokkan menjadi 5 jenis berdasarkan jumlah material organik (TOC) yaitu: poor source rock dengan nilai sebesar 0-0,5 wt.\% TOC, fair source rock dengan nilai antara 0,5-1 wt.\% TOC, good source rock dengan nilai 1-2 wt.\% TOC, very good source rok dengan nilai sebesar 2-4 wt.\% TOC, dan excellent dengan nilai lebih dari 4 wt. $\%$ TOC.

Batuan yang memiliki komposisi TOC kurang dari 0,5 wt.\% diartikan sebagai batuan yang memiliki potensi hidrokarbon dapat diabaikan (Dembicki, Jr., 2017). Batuan yang mempunyai komposisi TOC antara 0,5 wt. $\%-1,0$ wt.\% memiliki kemampuan yang terbatas (Wicaksana, 2018; Winegardner \& Testa, 2020). Kerogen dalam batuan yang mempunyai TOC kurang dari $1 \%$ secara umum telah teroksidasi, sehingga potensi untuk membentuk hidrokarbon terbatas. Batuan yang memiliki komposisi TOC lebih dari 1 wt.\% mempunyai potensi hidrokarbon yang besar. Sementara untuk TOC lebih dari 2 wt.\% menandakan lingkungan sangat reduksi dengan potensi hidrokarbon yang sangat baik (Curiale \& Curtis, 2016; Hartwig dkk., 2012).

Dalam kasus-kasus tertentu batuan mempunyai harga TOC tinggi, tapi mempunyai potensi rendah karena komposisi kerogen berupa material kayuan (woody) atau telah teroksidasi kuat (Rizqi \& Husein, 2017; Spigolon dkk., 2015). Tipe kerogen secara umum menurut Purnama dkk. (2020) dan Rahmola (2018) dapat diklasifikasikan menjadi 4 tipe seperti yang disajikan dalam Tabel 1. Kaitan antara tipe kerogen, jenis hidrokarbon yang dihasilkan, dan jumlah hidrogen menurut Laksono \& Manullang (2020) dan Millayanti dkk. (2019) adalah seperti yang tersaji dalam Tabel 2.

Vitrinite reflectance adalah indikator kematangan yang dilambangkan dengan Ro (Reflectance in oil). Nilai vitrinite reflectance dapat diketahui dari kemampuan kerogen memantulkan cahaya (Subroto, 2018). Metode untuk mengetahui vitrinite reflectance dilakukan dengan cara analisis kerogen. Sebelum kerogen dianalisis, sampel harus dipreparasi terlebih dahulu dengan cara dibersihkan kemudian diselubungi resin dan permukaannya dihaluskan. Pantulan diukur dengan menggunakan cahaya $(546 \mathrm{~nm})$ pada permukaan kerogen kemudian diamati dengan menggunakan mikroskop fotometer (Xiao dkk., 2019; Yang \& Zou, 2019). Semakin matang suatu kerogen maka akan memiliki nilai pantulan yang besar. Kerogen pada tahapan diagenesis hanya sedikit memantulkan cahaya sehingga memiliki nilai Ro dibawah $0,5 \%$ (immature) (Halim dkk., 2017). Ketika struktur kerogen semakin memadat dan teratur dalam proses katagenesis akan semakin memantulkan cahaya. Pada proses katagenesis akan memiliki kisaran nilai vitrinite reflectance sekitar $0,6 \%-1,35 \%$ dan mencapai maksimum pada nilai sekitar $0,8 \%-1 \%$ yang merupakan nilai pembentukan maksimal minyak bumi. Sedangkan pada proses metagenesis, memiliki nilai Ro diatas 2\% (Widagdo dkk., 2021; Sha dkk., 2020). Skala vitrinite relectance yang digunakan sebagai parameter kematangan batuan induk menurut Wang dkk. (2016) dapat dilihat pada Tabel 3.

Kebanyakan kerogen memasuki pembentukan minyak pada nilai Ro sekitar 0,6\%. Puncak pembentukan minyak bumi sampai sekitar Ro 0,9\%, dan akhir dari pembentukan minyak pada nilai Ro sekitar

Tabel 1 Tipe kerogen dan asal material organik menurut Purnama dkk. (2020) dan Rahmola (2018)

\begin{tabular}{lcc}
\hline Tipe Maseral & Kerogen & Asal Material Organik \\
\hline Alginit & I & Alga airtawar \\
Eksinit & II & Polen, spora \\
Kutinit & II & Lapisan lilin tanaman \\
Resinit & II & Resin tanaman \\
Liptinit & II & Lemak tanaman, alga laut \\
Vitrinit & III & Material tumbuhan tingkat tinggi \\
Inertinit & IV & Arang, material teroksidasi \\
\hline
\end{tabular}

Tabel 2 Tipe kerogen, potensi hidrokarbon, dan jumlah hidrogen menurut Millayanti dkk. (2019)

\begin{tabular}{lcc}
\hline Tipe & Potensi Hidrokarbon & Jumlah Hidrogen \\
\hline I & Minyak & Melimpah \\
II & Minyak dan gas & Sedang \\
III & Gas & Sedikit \\
IV & Tidak berpotensi & Tidak ada \\
\hline
\end{tabular}




\section{TEKNIK, 42 (3), 2021, 263}

Tabel 3 Tingkat kematangan batuan induk berdasarkan vitrinite reflectance

\begin{tabular}{lc}
\hline Ro $(\%)$ & Tingkat Kematangan \\
\hline$<0,6$ & immature \\
$0,6-0,65$ & early mature \\
$0,65-0,90$ & peak mature \\
$0,9-1,35$ & late mature \\
$>1,35$ & postmature \\
\hline
\end{tabular}

$1,35 \%$. Kemudian pada nilai Ro sekitar $1,5 \%$ mulai terjadi pembentukan gas. Tingkat kematangan termal yang sangat baik pada Ro antara $0,7 \%$ dan $0,8 \%$ (G. C. Wang dkk., 2018).

Rock eval pyrolisis merupakan analisis komponen hidrokarbon pada batuan induk dengan cara melakukan pemanasan bertahap pada sampel batuan induk dalam keadaan tanpa oksigen pada kondisi atmosfer inert dengan temperatur yang terprogram. Analisis rock eval pyrolisis dilakukan dengan menggunakan pemanas (oven) yang dinyalakan pada suhu atmosfer inert (Helium) yaitu $25^{\circ} \mathrm{C} /$ menit. Hasil analisis rock eval pyrolisis dapat menentukan hidrokarbon bebas di dalam sampel, senyawa hidrokarbon dan oksigen yang menguap sejak proses cracking material organik di dalam sampel (kerogen) (Słowakiewicz dkk., 2020).

Proses analisis rock eval pyrolisis dapat dijelaskan sebagai berikut: selama 3 menit pertama sampel yang telah dihancurkan dan dikeringkan dipanasi dengan oven pada suhu $200^{\circ} \mathrm{C}$, sehingga hidrokarbon bebas menguap. Jumlah hidrokarbon bebas yang menguap diukur sebagai puncak S1. Kemudian temperatur dinaikkan lagi dari $200^{\circ} \mathrm{C}$ hingga mencapai $550^{\circ} \mathrm{C}$ dengan kenaikan $25^{\circ} \mathrm{C}$ /menit. Ini merupakan fase penguapan hidrokarbon berat $(>\mathrm{C} 40)$ dan juga proses pemecahan rantai karbon organik yang tidak menguap. Hidrokarbon yang dikeluarkan tersebut diukur sebagai puncak S2. Temperatur pada puncak S2 tersebut merupakan temperatur pematangan kerogen yang disebut Tmax. Setelah mencapai suhu $550^{\circ} \mathrm{C}$, secara perlahan temperatur diturunkan. Pada temperatur antara $300^{\circ} \mathrm{C}-390^{\circ} \mathrm{C} \quad \mathrm{CO}_{2}$ akan dikeluarkan dari kerogen. Perangkap tersebut dipanaskan dan $\mathrm{CO}_{2}$ dilepaskan dan dideteksi oleh TCD sejak proses pendinginan oven pyrolisis (S3) (Aziz dkk., 2020).

Hasil analisis rock eval pyrolisis berupa data S1, S2, S3 dan Tmax. S1 merupakan total hidrokarbon bebas yang terdapat di dalam sampel dan biasa dinyatakan dalam satuan miligram hidrokarbon per satu gram batuan. Sementara itu, S2 merupakan total hidrokarbon yang dihasilkan melalui cracking material organik yang tidak menguap (Liu dkk., 2020). Data S3 merupakan total $\mathrm{CO}_{2}$ dalam miligram $\mathrm{CO}_{2}$ per gram batuan yang dihasilkan selama pyrolisis kerogen (Sokol dkk., 2014).

Tmax adalah temperatur maksimum untuk melepas hidrokarbon dari proses pemecahan kerogen yang terjadi selama pyrolisis (puncak S2). Jika Tmax menunjukkan nilai kurang dari $435^{\circ} \mathrm{C}$ maka perubahan material organik masih berupa biogenic gas, sedangkan nilai Tmax antara $435^{\circ} \mathrm{C}-470^{\circ} \mathrm{C}$ menunjukkan perubahan material organik telah menghasilkan minyak atau gas bumi, dan jika nilai suhu maksimum lebih dari $470^{\circ} \mathrm{C}$ maka perubahan material organik telah menghasilkan dry gas (Bojesen-Koefoed dkk., 2020; Laksono, Ramadhan, dkk., 2020).

HI atau indeks hidrogen adalah parameter yang digunakan untuk menjelaskan asal material organik misalnya dari darat, transisi, atau marine. Persamaan 1 digunakan untuk menentukan indeks hidrogen (Ogala dkk., 2019)

$$
\mathrm{HI}=(100 \times \mathrm{S} 2) / \mathrm{TOC}
$$

dimana $\mathrm{HI}$ adalah indeks hidrogen (mgHC/gr TOC), S2 adalahjumlah hidrokarbon tidak menguap, dan TOC adalah jumlah karbon organik (wt.\%).

Oil Production Index (OPI) atau sering disebut dengan Production Index (PI) menunjukkan perbandingan antara jumlah relatif hidrokarbon bebas dengan jumlah total hidrokarbon yang ada (Adeoye dkk., 2020; Chen dkk., 2020). Indeks produksi dapat dicari dengan menggunakan persamaan 2 (Craig dkk., 2018).

$$
\mathrm{PI}=\mathrm{S} 1 /(\mathrm{S} 1+\mathrm{S} 2)
$$

dimana PI adalah indeks produksi minyak bumi sedangkan $\mathrm{S} 1$ adalah jumlah hidrokarbon bebas.

Potential Yield (PY) atau potensi hasil menunjukkan jumlah total hidrokarbon yang terdapat di source rock baik yang berupa komponen volatil maupun yang berupa kerogen. Potential Yield dapat dicari menggunakan persamaan 3 (Cheng dkk., 2018)

$$
\mathrm{PY}=\mathrm{S} 1+\mathrm{S} 2
$$

dimana PY adalah Potential Yield atau potensi hasil minyak bumi.

Skala nilai penentuan potensi batuan induk dengan menggabungkan semua parameter seperti TOC, vitrinite reflectance, hingga rock eval pyrolisis dapat ditunjukkan dalam Tabel 4, 5, dan 6. 


\section{TEKNIK, 42 (3), 2021, 264}

Tabel 4 Potensi pembentukan hidrokarbon berdasarkan parameter geokimia batuan induk (Xiao dkk., 2019)

\begin{tabular}{lccccc}
\hline Potensial & TOC (wt. \%) & S1 & S2 & Bitumen (ppm) & Hidrokarbon (ppm) \\
\hline Buruk & $<0,5$ & $<0,5$ & $<2,5$ & $<500$ & $<300$ \\
Sedang & $0,5-1$ & $0,5-1$ & $2,5-5$ & $500-1000$ & $300-600$ \\
Baik & $1-2$ & $1-2$ & $5-10$ & $1000-2000$ & $600-1200$ \\
Sangat baik & $2-4$ & $2-4$ & $10-20$ & $2000-4000$ & $1200-2400$ \\
Sempurna & $>4$ & $>4$ & $>20$ & $>4000$ & $>2400$ \\
\hline
\end{tabular}

Tabel 5 Tipe kerogen dan jenis hidrokarbon yang dihasilkan menurut G. C. Wang dkk. (2018)

\begin{tabular}{ccccc}
\hline Kerogen & HI $(\mathbf{m g H C} / \mathbf{g r}$ TOC $)$ & S2/S3 & Atom H/C & Jenis Hidrokarbon \\
\hline I & $>600$ & $>15$ & $>1,5$ & Minyak bumi \\
II & $300-600$ & $10-15$ & $1,2-1,5$ & Minyak bumi \\
II/III & $200-300$ & $5-10$ & $1-1,2$ & Minyak dan gas bumi \\
III & $50-200$ & $1-5$ & $0,7-1$ & Gas bumi \\
IV & $<50$ & $<1$ & $<0,7$ & Tidak berpotensi \\
\hline
\end{tabular}

Tabel 6 Kematangan suhu menurut P. C. Wang dkk. (2016)

\begin{tabular}{lcccccc}
\hline Potensial & Ro $(\%)$ & Tmax $\left({ }^{\mathbf{0}} \mathbf{C}\right)$ & TAI & Bitumen/TOC & Bitumen $(\mathbf{m g} / \mathbf{g r}$ rock) & PI \\
\hline Belum matang & $<0,6$ & $<435$ & $1,5-2,6$ & $<0,05$ & $<50$ & $<0,1$ \\
Awal matang & $0,6-0,65$ & $435-445$ & $2,6-2,7$ & $0,05-0,1$ & $50-100$ & $0,1-0,15$ \\
Puncak matang & $0,65-0,9$ & $445-450$ & $2,6-2,7$ & $0,15-0,25$ & $150-250$ & $0,25-0,4$ \\
Akhir matang & $0,9-1,35$ & $450-470$ & $2,9-3,3$ & - & - & $>0,4$ \\
Terlalu matang & $>1,35$ & $>470$ & $>3,3$ & - & - & - \\
\hline
\end{tabular}

\section{Hasil dan Pembahasan}

Data geokimia Formasi Naintupo ada di 6 sumur eksplorasi. Formasi Naintupo di Sumur South Sembakung-1 berada di kedalaman 9352-11.000 ft, Sembakung-2 pada kedalaman 8400-10.000 ft, Tanjung Kramat-1 pada kedalaman 5623-7590 ft, Tanjung Bimau1 pada kedalaman 5085-6890 ft, Daino-1 pada kedalaman $6930 \mathrm{ft}-7730 \mathrm{ft}$, dan Sesayap E-1 pada kedalaman $9490 \mathrm{ft}-10.500 \mathrm{ft}$. Berdasarkan analisis terhadap data-data geokimia, Formasi Naintupo yang berada di Sumur South Sembakung-1, Tanjung Kramat-1, Tanjung Bimau-1, dan Sesayap E-1 memiliki potensi gas bumi yang cukup baik, sedangkan di Sumur Sembakung2 memiliki sedikit potensi gas. Di Sumur South Sembakung-1, Tanjung Kramat-1, Tanjung Bimau-1, dan Sesayap E-1 secara umum memiliki TOC tergolong baiksangat baik karena nilai rata-ratanya sekitar 1 wt.\% hingga diatas 4 wt.\% terutama di Sumur Daino-1. Sementara itu, di Sumur Sembakung-2 memiliki TOC hanya $0,99 \mathrm{wt} \%$ yang tergolong sedang atau cukup. Nilai HI di ke 6 sumur eksplorasi menunjukkan jenis kerogen III yang didominasi vitrinit atau tumbuhan berkayu yang berasal dari darat, OPI rata-rata diatas $0,1 \%$ yang tergolong sudah memungkinkan menghasilkan hidrokarbon jenis gas bumi, serta Tmax dan Ro tergolong mature dengan nilai lebih dari $435^{\circ} \mathrm{C}$ untuk Tmax dan $0,6 \%$ untuk Ro. Salah satu contoh diagram analisis geokimia Formasi Naintupo di Sumur Sesayap E-1 dapat ditunjukkan dengan Gambar 2 dan 3.

Gambar 2 menunjukkan bahwa Formasi Naintupo di Sumur Sesayap E-1 yang berada di kedalaman 9490-10.500 ft dan ditandai dengan kotak berwarna merah mempunyai indeks nilai TOC antara 1,41-1,76 wt.\%, sementara nilai OPI sebesar 0,22-0,65, dan $\mathrm{S} 1$ sebesar 0,42-2,18. Pada gambar tersebut sumbu x merupakan nilai TOC, OPI, dan S1, sedangkan sumbu y menunjukkan kedalaman formasi batuan dalam satuan feet (ft). Sedangkan pada Gambar 3 menunjukkan indeks nilai HI, Tmax, dan Ro Formasi Naintupo di Sumur Sesayap E-1 pada kedalaman $9490 \mathrm{ft}-10.500 \mathrm{ft}$ secara berturut-turut sebesar $52 \mathrm{mgHC} / \mathrm{gr}$ TOC sampai $106 \mathrm{mgHC} / \mathrm{gr}$ TOC, 464oC-471oC dan 0,78\%-0,82\%.

Berdasarkan penjelasan di atas dapat diketahui bahwa Formasi Naintupo memiliki kelimpahan material organik yang tergolong baik, mempunyai tipe kerogen III yang memungkinkan dapat menghasilkan hidrokarbon jenis gas bumi, memiliki tingkat kematangan yang tergolong mature sehingga kemungkinan besar telah terjadi proses produksi hidrokarbon yang diperkuat berdasarkan nilai OPI yang lebih dari 0,1 . Hal tersebut menandakan bahwa mungkin telah terjadi ekspulsi hidrokarbon jenis gas bumi dalam volume yang cukup besar. Jadi berdasarkan bukti-bukti tersebut memungkinkan Formasi Naintupo dapat menjadi batuan induk efektif. 
TEKNIK, 42 (3), 2021, 265

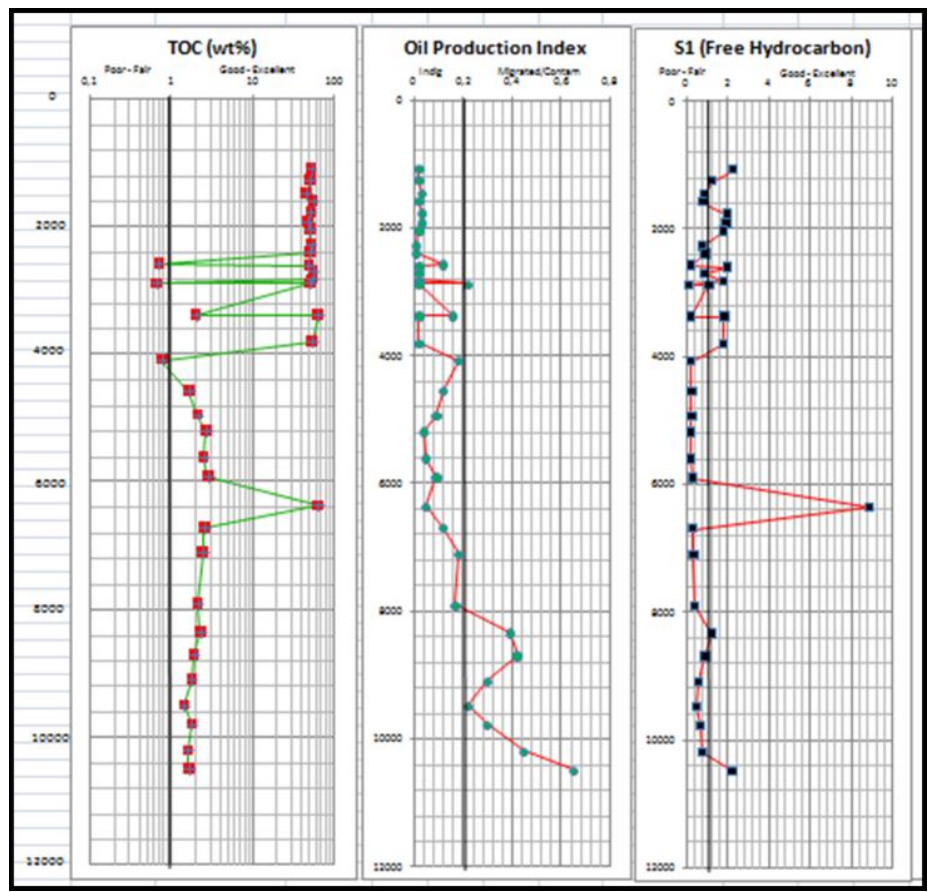

Gambar 2 Diagram analisis TOC, OPI, dan S1 Formasi Naintupo di Sumur Sesayap E-1 ditunjukkan dengan kotak berwarna merah.

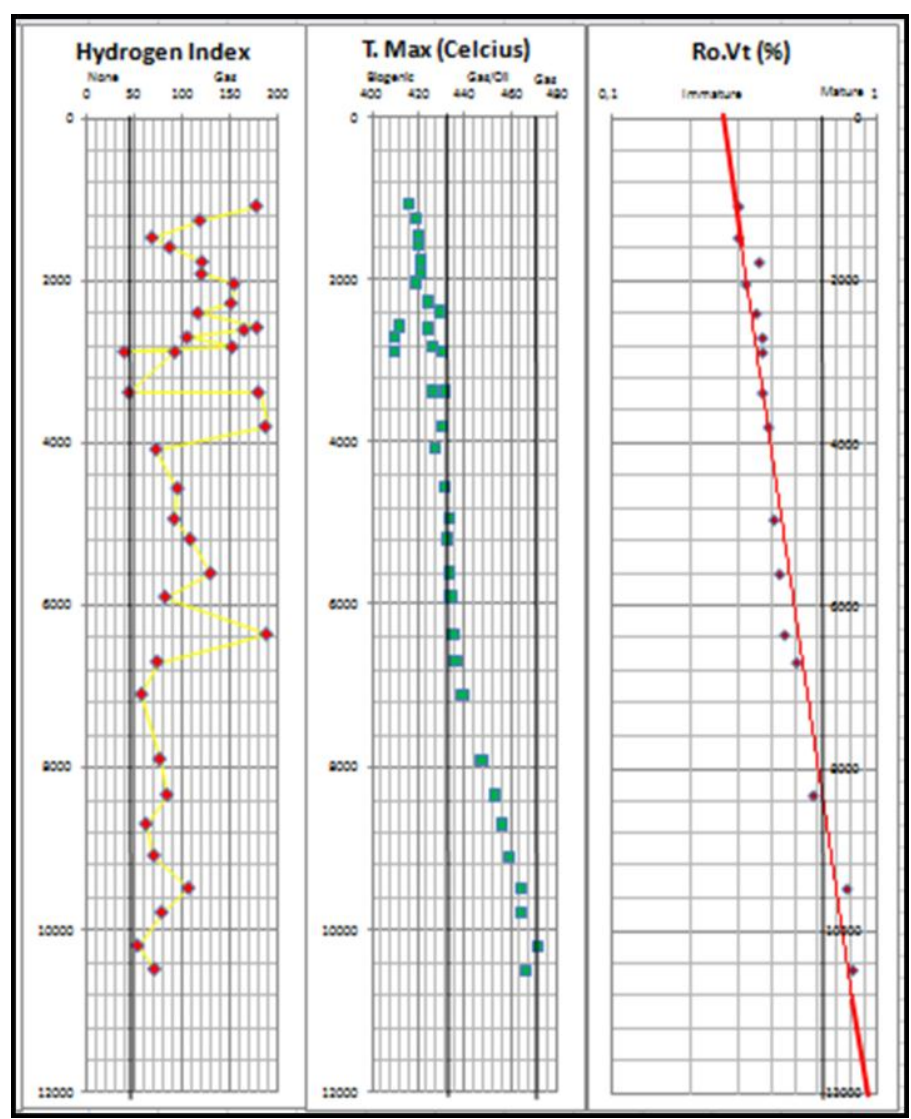

Gambar 3 Diagram analisis HI, Tmax, dan Ro Formasi Naintupo di Sumur Sesayap E-1 ditunjukkan dalam kotak bergaris merah. 


\section{TEKNIK, 42 (3), 2021, 266}

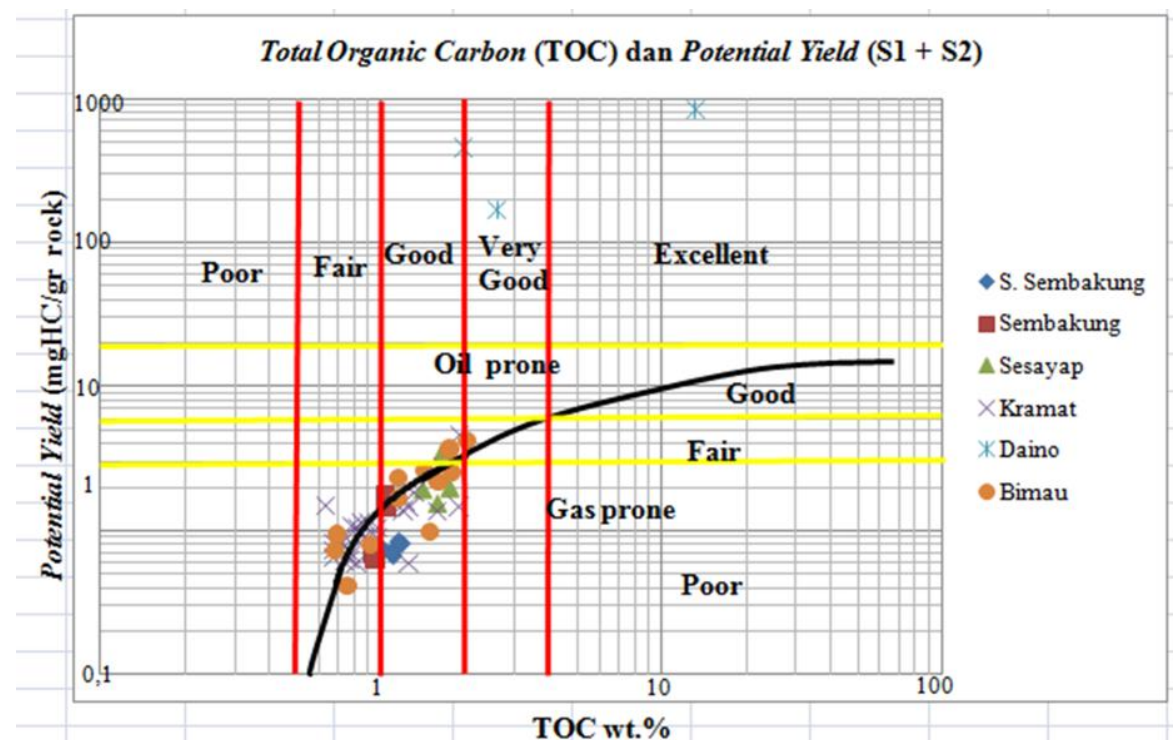

Gambar 4 Diagram hubungan antara nilai PY dan TOC Formasi Naintupo.

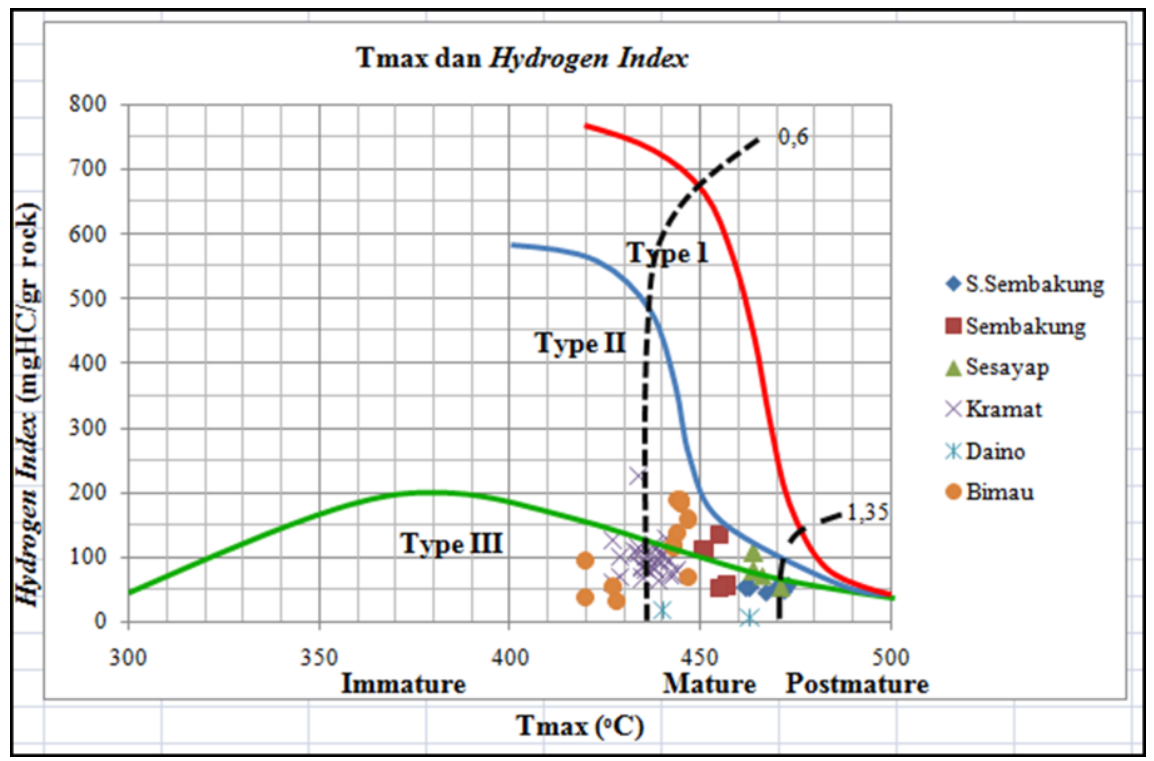

Gambar 5 Diagram hubungan Tmax dan Hydrogen Index Formasi Naintupo.

Diagram hubungan antara potential yield dengan TOC dapat mengetahui persebaran potensi hidrokarbon yang dihasilkan oleh suatu formasi batuan pada sumursumur eksplorasi yang ada di daerah penelitian. Potential yield adalah hasil penjumlahan antara S1 dan S2. S1 merupakan total hidrokarbon bebas yang terdapat di dalam sampel dan dinyatakan dalam satuan miligram hidrokarbon per satu gram batuan. Sementara itu, S2 adalah total hidrokarbon yang dihasilkan oleh cracking material organik yang tidak menguap, dengan kata lain dapat diartikan sebagai indikasi kuantitas potensi hidrokarbon yang dapat dihasilkan kerogen melalui pematangan. Gambar 4 di bawah ini adalah diagram hubungan antara potential yield dengan TOC Formasi Naintupo di 6 sumur eksplorasi.

Diagram di atas dapat memberikan informasi bahwa pengeplotan nilai PY dan TOC Formasi Naintupo di 6 sumur eksplorasi yaitu Daino-1, South Sembakung1, Sembakung-2, Tanjung Kramat-1, Tanjung Bimau-1, dan Sesayap E-1 lebih banyak terakumulasi pada bagian bawah dari garis trend. Hal tersebut ditunjukkan dengan nilai-nilai TOC dan PY di 6 sumur eksplorasi yang lebih banyak berada di bagian bawah garis trend. Akumulasi yang bersifat demikian, dapat diinterpretasikan bahwa 


\section{TEKNIK, 42 (3), 2021, 267}

Tabel 7. Data geokimia Formasi Naintupo di Sumur Sembakung, Sesayap, dan Kramat

\begin{tabular}{lcccccccc}
\hline Kedalaman (ft) & Formasi & Sumur & TOC (wt\%) & HI (mg) & Ro (\%) & Tmax $\left({ }^{\mathbf{0}} \mathbf{C}\right)$ & PI & PY \\
\hline 9580 & Naintupo & S.Sembakung & 1,14 & 53 & 0,8 & 463 & 0,22 & 0,77 \\
9800 & Naintupo & S.Sembakung & 1,19 & 53 & 0,82 & 462 & 0,23 & 0,82 \\
10.180 & Naintupo & S.Sembakung & 1,11 & 46 & 0,85 & 467 & 0,24 & 0,67 \\
10.480 & Naintupo & S.Sembakung & 1,16 & 54 & 0,9 & 470 & 0,26 & 0,85 \\
\hline
\end{tabular}

Formasi Naintupo cenderung berpotensi menghasilkan gas bumi. Pembuatan diagram hubungan antara TOC dan PY pada Gambar 4 berdasarkan klasifikasi parameter geokimia batuan induk (Hackley dkk., 2020). Pada klasifikasi tersebut disebutkan bahwa nilai TOC antara $0 \%-0,5 \%$ tergolong poor atau miskin material organik. Nilai TOC antara $0,5 \%-1 \%$ dianggap mempunyai material organik dalam jumlah yang sedang/fair. Nilai TOC antara 1\%-2\% tergolong mempunyai keterdapatan material organik yang baik/good. Nilai TOC antara 2\%-4\% dianggap mempunyai keterdapatan material organik dalam kategori yang sangat baik/very good, sedangkan nilai TOC lebih dari $4 \%$ dianggap memiliki keterdapatan material organik dalam jumlah yang melimpah/excellent. Nilai potential yield yang berada dibawah $2 \mathrm{mgHC} / \mathrm{gr}$ TOC tergolong poor, nilai PY antara 2-6 mgHC/gr TOC tergolong fair, nilai PY antara 6-20 mgHC/gr TOC tergolong good, dan nilai PY lebih dari $20 \mathrm{mgHC} / \mathrm{gr}$ TOC tergolong excellent.

Sementara itu, untuk mengetahui persebaran tipe kerogen, besarnya kematangan, dan memperkuat jenis potensi hidrokarbon yang dihasilkan oleh Formasi Naintupo di 6 sumur eksplorasi dapat dilakukan dengan membuat diagram hubungan antara Tmax dan HI. Diagram hubungan antara Tmax dan HI Formasi Naintupo di 6 sumur eksplorasi dapat dilihat seperti pada Gambar 5. Pada Gambar 5 dapat diketahui bahwa akumulasi pengeplotan nilai Tmax dan HI lebih banyak berada di tipe kerogen III dengan kematangan cenderung mature. Hal tersebut dapat diinterpretasikan bahwa tipe kerogen yang terdapat di Formasi Naintupo lebih didominasi tipe kerogen III yang biasanya berasal dari tumbuhan berkayu atau tumbuhan tingkat tinggi yang umumnya banyak hidup di darat. Sehingga dapat diartikan pula Formasi Naintupo lebih banyak mendapatkan suplai material organik yang berasal dari darat atau terestrial. Selain itu, di Formasi Naintupo terdapat pula kerogen tipe II walaupun dalam jumlah yang tidak sebanyak tipe kerogen III. Artinya selain adanya suplai material organik dari darat, pembentukan Formasi Naintupo juga mendapatkan pengaruh dari suplai material organik laut dangkal. Hal tersebut karena tipe kerogen II biasanya berasal dari tipe maseral eksinit, kutinit, resinit, dan liptinit. Tipe maseral eksinit seperti polen dan spora. Tipe maseral kutinit seperti lapisan lilin pada tanaman. Tipe maseral resinit seperti resin tanaman, sedangkan tipe maseral liptinit seperti lemak tanaman atau alga laut. Pembuatan diagram hubungan antara Tmax dan HI berdasarkan klasifikasi parameter geokimia batuan induk menurut Peters dkk. (2005). Dalam klasifikasi tersebut disebutkan bahwa nilai indeks hidrogen antara 50-200 mgHC/gr TOC didominasi oleh tipe kerogen III. Nilai HI antara 200-300 mgHC/gr TOC didominasi tipe kerogen II/III, nilai HI antara 300-600 $\mathrm{mgHC} / \mathrm{gr}$ TOC didominasi tipe kerogen II, dan nilai HI lebih dari $600 \mathrm{mgHC} / \mathrm{gr}$ TOC didominasi tipe kerogen I. Nilai Tmax kurang dari $435^{\circ} \mathrm{C}$ tergolong immature, nilai Tmax antara $435^{\circ} \mathrm{C}-470^{\circ} \mathrm{C}$ tergolong mature, dan nilai Tmax lebih dari $470^{\circ} \mathrm{C}$ tergolong postmature.

Tabel 7 dan 8 menunjukkan data geokimia Formasi Naintupo di Sumur South Sembakung-1, Sembakung-2, Sesayap E-1, Tanjung Kramat-1, Tanjung Kramat-1, Daino-1, dan Tanjung Bimau-1. Berdasarkan data tersebut rata-rata kematangan hidrokarbon yang sesuai untuk pembentukan minyak bumi terjadi pada kedalaman antara 8000-10.000 ft. Hal itu berarti batas kematangan Formasi Naintupo berada pada kedalaman tersebut.

Hasil kajian ini memperkuat penelitian Husein (2017) dan Nugroho dkk. (2018) yang menyatakan bahwa Formasi Naintupo adalah salah satu formasi batuan yang berpotensi menghasilkan hidrokarbon selain Formasi Tabul, Meliat, dan Tabalar. Akan tetapi, pada penelitian sebelumnya hanya menggunakan data geofisika dan geologi permukaan yang tingkat kepastiannya masih sangat rendah. Melalui data geokimia bawah permukaan ini maka hipotesis pada penelitian sebelumnya menjadi terbukti. Selain itu studi ini berhasil menjawab pertanyaan penelitian Wijaya dkk. (2012) yang belum dapat memastikan jenis hidrokarbon di Formasi Naintupo. Tipe kerogen III yang mendominasi kandungan material organik di Formasi Naintupo menunjukkan bahwa jenis hidrokarbon yang paling berpotensi adalah gas bumi. 


\section{TEKNIK, 42 (3), 2021, 268}

Tabel 8. Data geokimia Formasi Sembakung, Sesayap, Kramat, Daino, dan Bimau

\begin{tabular}{|c|c|c|c|c|c|c|c|c|}
\hline Kedalaman (ft) & Formasi & Sumur & TOC (wt\%) & HI (mg) & $\operatorname{Ro}(\%)$ & $\operatorname{Tmax}\left({ }^{\circ} \mathrm{C}\right)$ & PI & PY \\
\hline 10.800 & Naintupo & S.Sembakung & 1,01 & 57 & 0,92 & 473 & 0,24 & 0,76 \\
\hline 10.980 & Naintupo & S.Sembakung & 1,09 & 48 & 0,92 & 472 & 0,26 & 0,7 \\
\hline 8400 & Naintupo & Sembakung & 1,05 & 112 & 0,72 & 451 & 0,19 & 1,46 \\
\hline 8600 & Naintupo & Sembakung & 1,04 & 134 & 0,75 & 455 & 0,21 & 1,75 \\
\hline 9800 & Naintupo & Sembakung & 0,94 & 56 & 0,8 & 457 & 0,19 & 0,68 \\
\hline 9990 & Naintupo & Sembakung & 0,96 & 51 & 0,81 & 455 & 0,22 & 0,63 \\
\hline 9490 & Naintupo & Sesayap & 1,41 & 106,3 & 0,78 & 464 & 0,22 & 1,92 \\
\hline 9790 & Naintupo & Sesayap & 1,76 & 78,4 & 0,72 & 464 & 0,3 & 1,97 \\
\hline 10.200 & Naintupo & Sesayap & 1,59 & 52,8 & 0,79 & 471 & 0,45 & 1,53 \\
\hline 10.490 & Naintupo & Sesayap & 1,63 & 70,5 & 0,82 & 466 & 0,65 & 3,33 \\
\hline 5623 & Naintupo & Kramat & 0,68 & 79 & 0,52 & 436 & 0,16 & 0,64 \\
\hline 5629 & Naintupo & Kramat & 0,79 & 113 & 0,57 & 434 & 0,17 & 1,07 \\
\hline 5636 & Naintupo & Kramat & 1,91 & 225 & 0,53 & 434 & 0,07 & 4,62 \\
\hline 5643 & Naintupo & Kramat & 0,91 & 107 & 0,64 & 433 & 0,13 & 1,12 \\
\hline 5649 & Naintupo & Kramat & 1,9 & 67 & 0,64 & 435 & 0,13 & 1,47 \\
\hline 5841 & Naintupo & Kramat & 1,59 & 60 & 0,51 & 427 & 0,29 & 1,35 \\
\hline 5905 & Naintupo & Kramat & 1,26 & 100 & 0,52 & 436 & 0,13 & 1,44 \\
\hline 6003 & Naintupo & Kramat & 0,75 & 85 & 0,52 & 435 & 0,3 & 0,91 \\
\hline 6069 & Naintupo & Kramat & 1,23 & 118 & 0,52 & 438 & 0,09 & 1,6 \\
\hline 6095 & Naintupo & Kramat & 1,26 & 104 & 0,55 & 437 & 0,1 & 0,59 \\
\hline 6233 & Naintupo & Kramat & 0,64 & 83 & 0,56 & 438 & 0,13 & 1,5 \\
\hline 6315 & Naintupo & Kramat & 0,68 & 68 & 0,56 & 429 & 0,36 & 0,72 \\
\hline 6397 & Naintupo & Kramat & 1,2 & 106 & 0,54 & 439 & 0,08 & 1,38 \\
\hline 6400 & Naintupo & Kramat & 1,67 & 125 & 0,57 & 427 & 0,25 & 2,79 \\
\hline 6414 & Naintupo & Kramat & 0,83 & 100 & 0,52 & 429 & 0,2 & 1,04 \\
\hline 6561 & Naintupo & Kramat & 0,98 & 95 & 0,54 & 439 & 0,09 & 1,03 \\
\hline 6725 & Naintupo & Kramat & 0,98 & 79 & 0,54 & 438 & 0,13 & 0,88 \\
\hline 6889 & Naintupo & Kramat & 1,32 & 129 & 0,56 & 441 & 0,08 & 1,85 \\
\hline 6906 & Naintupo & Kramat & 0,85 & 106 & 0,49 & 434 & 0,21 & 1,14 \\
\hline 7041 & Naintupo & Kramat & 0,88 & 83 & 0,52 & 435 & 0,18 & 0,89 \\
\hline 7053 & Naintupo & Kramat & 0,68 & 106 & 0,49 & 440 & 0,12 & 0,82 \\
\hline 7135 & Naintupo & Kramat & 0,82 & 63 & 0,56 & 439 & 0,12 & 0,59 \\
\hline 7217 & Naintupo & Kramat & 0,72 & 94 & 0,58 & 442 & 0,07 & 0,73 \\
\hline 7299 & Naintupo & Kramat & 0,73 & 101 & 0,59 & 440 & 0,1 & 0,82 \\
\hline 7381 & Naintupo & Kramat & 0,78 & 73 & 0,65 & 443 & 0,08 & 0,62 \\
\hline 7463 & Naintupo & Kramat & 0,74 & 73 & 0,58 & 442 & 0,11 & 0,61 \\
\hline 7545 & Naintupo & Kramat & 0,79 & 78 & 0,67 & 444 & 0,09 & 0,68 \\
\hline 6930 & Naintupo & Daino & 13,2 & 13 & 1,3 & 543 & 0,07 & 850 \\
\hline 7210 & Naintupo & Daino & 2,59 & 6 & 1,34 & 463 & 0,23 & 170 \\
\hline 7730 & Naintupo & Daino & 1,97 & 18 & 1,35 & 440 & 0,13 & 460 \\
\hline 5249 & Naintupo & Bimau & 2,02 & 187 & 1,64 & 444 & 0,10 & 4,24 \\
\hline 5413 & Naintupo & Bimau & 1,75 & 184 & 1,07 & 445 & 0,13 & 3,72 \\
\hline 5638 & Naintupo & Bimau & 1,49 & 36,9 & 1,74 & 420 & 0,43 & 0,97 \\
\hline 5741 & Naintupo & Bimau & 1,43 & 158 & 0,48 & 447 & 0,14 & 2,64 \\
\hline 5860 & Naintupo & Bimau & 0,76 & 31,6 & 1,79 & 428 & 0,41 & 0,41 \\
\hline 5955 & Naintupo & Bimau & 0,69 & 68,1 & 2,38 & 447 & 0,35 & 0,73 \\
\hline 6234 & Naintupo & Bimau & 1,79 & 117 & 2,12 & 443 & 0,18 & 2,58 \\
\hline 6562 & Naintupo & Bimau & 1,15 & 186 & 2,1 & 445 & 0,08 & 2,34 \\
\hline 6726 & Naintupo & Bimau & 1,15 & 136,5 & 2,19 & 444 & 0,07 & 1,69 \\
\hline 6785 & Naintupo & Bimau & 0,92 & 54,3 & 2,19 & 427 & 0,36 & 0,79 \\
\hline 6831 & Naintupo & Bimau & 0,7 & 94,3 & 2,25 & 420 & 0,29 & 0,93 \\
\hline
\end{tabular}




\section{TEKNIK, 42 (3), 2021, 269}

\section{Kesimpulan}

Analisis Ro menunjukkan bahwa Formasi Naintupo memiliki kematangan material organik. Nilai rata-rata Ro berada pada rentang $0,6 \%-1,35 \%$. Formasi Naintupo mempunyai keterdapatan material organik yang baik berdasarkan nilai TOC rata-rata yang lebih dari $1 \mathrm{wt} . \%$ namun didominasi tipe kerogen III dengan nilai rata-rata $\mathrm{HI}$ antara $50 \mathrm{mgHC} / \mathrm{gr}$ TOC hingga 200 $\mathrm{mgHC} / \mathrm{gr}$ TOC. Oleh karena itu, jenis hidrokarbon yang paling berpotensi adalah gas bumi. Potensi gas bumi terbesar berada di Sumur South Sembakung-1, Tanjung Bimau-1, Sesayap E-1, dan Tanjung Kramat-1 dengan kedalaman antara 9394-11.000 ft atau dengan ketebalan rata-rata $1606 \mathrm{ft}$. Hasil analisis menunjukkan bahwa Formasi Naintupo berpotensi menghasilkan gas bumi di Sub-Cekungan Tarakan.

\section{Ucapan Terima Kasih}

Terima kasih kepada Universitas Jenderal Soedirman dan Medco E\&P Indonesia yang telah memfasilitasi dan memberikan dukungan dana dalam pelaksanaan penelitian eksplorasi potensi gas alam di Sub-Cekungan Tarakan, Provinsi Kalimanatan Utara.

\section{Daftar Pustaka}

Abdullah, W. H., Togunwa, O. S., Makeen, Y. M., Hakimi, M. H., Mustapha, K. A., Baharuddin, M. H., Sia, S. G., \& Tongkul, F. (2017). Hydrocarbon Source Potential of Eocene-Miocene Sequence of Western Sabah, Malaysia. Marine and Petroleum Geology, 83(1), 345-361. https://doi.org/10.1016/j.marpetgeo.2017.02.031

Adeoye, J. A., Akande, S. O., Adekeye, O. A., Sonibare, W. A., Ondrak, R., Dominik, W., Erdtmann, B. D., \& Neeka, J. (2020). Source Rock Maturity and Petroleum Generation in the Dahomey Basin SW Nigeria: Insights from Geologic and Geochemical Modelling. Journal of Petroleum Science and Engineering, 195(2), 1-17. https://doi.org/10.1016/j.petrol.2020.107844

Al-Areeq, N. M. (2018). Petroleum Source Rocks Characterization and Hydrocarbon Generation (p. 28). London: Intech Open Publisher https://doi.org/10.5772/intechopen.70092

Aziz, H., Ehsan, M., Ali, A., Khan, H. K., \& Khan, A. (2020). Hydrocarbon Source Rock Evaluation and Quantification of Organic Richness from Correlation of Well Logs and Geochemical Data: a Case Study from the Sembar Formation, Southern Indus Basin, Pakistan. Journal of Natural Gas Science and Engineering, 81(2), 1-14. https://doi.org/10.1016/j.jngse.2020.103433

Bojesen-Koefoed, J. A., Alsen, P., Bjerager, M.,
Hovikoski, J., Ineson, J., Nytoft, H. P., NøhrHansen, H., Petersen, H. I., Pilgaard, A., \& Vosgerau, H. (2020). A mid-Cretaceous Petroleum Source-Rock in the North Atlantic Region? Implications of the Nanok-1 Fully Cored Borehole, Hold with Hope, Northeast Greenland. Marine and Petroleum Geology, 117(1), 1-12. https://doi.org/10.1016/j.marpetgeo.2020.104414

Chen, Z., Lavoie, D., Mort, A., Jiang, C., Zhang, S., Liu, X., Reyes, J., \& Armstrong, D. (2020). Source Rock Kinetics and Petroleum Generation History of the Upper Ordovician Calcareous Shales of the Hudson Bay Basin and Surrounding Areas. Fuel, 270(1), $1-16$. https://doi.org/10.1016/j.fuel.2020.117503

Chen, Z., Liu, X., Guo, Q., Jiang, C., \& Mort, A. (2017). Inversion of Source Rock Hydrocarbon Generation Kinetics from Rock-Eval Data. Fuel, 194(1), 91-101. https://doi.org/10.1016/j.fuel.2016.12.052

Cheng, B., Chen, Z., Chen, T., Yang, C., \& Wang, T. G. (2018). Biomarker Signatures of the EdiacaranEarly Cambrian Origin Petroleum from the Central Sichuan Basin, South China: Implications for Source Rock Characteristics. Marine and Petroleum Geology, 96(2), 577-590. https://doi.org/10.1016/j.marpetgeo.2018.05.012

Craig, J., Hakhoo, N., Bhat, G. M., Hafiz, M., Khan, M. R., Misra, R., Pandita, S. K., Raina, B. K., Thurow, J., Thusu, B., Ahmed, W., \& Khullar, S. (2018). Petroleum Systems and Hydrocarbon Potential of the North-West Himalaya of India and Pakistan. In Earth-Science Reviews, 187(2), 109185. https://doi.org/10.1016/j.earscirev.2018.09.012

Curiale, J. A. (2017). Total Organic Carbon (TOC) (p. 5). New York: Springer Publishing. https://doi.org/10.1007/978-3-319-02330-4_3-1

Curiale, J. A., \& Curtis, J. B. (2016). Organic Geochemical Applications to the Exploration for Source-Rock Reservoirs - a Review. Journal of Unconventional Oil and Gas Resources, 13(1), 131. https://doi.org/10.1016/j.juogr.2015.10.001

Dembicki, Jr., H. (2017). Source Rock Evaluation in Practical Petroleum Geochemistry for Exploration and Production (p. 129). Amsterdam: Elsevier Publishing

Company. https://doi.org/10.1016/b978-0-12-8033500.00003-9

Hackley, P. C., Dennen, K. O., Garza, D., Lohr, C. D., Valentine, B. J., Hatcherian, J. J., Enomoto, C. B., \& Dulong, F. T. (2020). Oil-Source Rock Correlation Studies in the Unconventional Upper Cretaceous Tuscaloosa Marine Shale (TMS) Petroleum System, Mississippi and Louisiana, 


\section{TEKNIK, 42 (3), 2021, 270}

USA. Journal of Petroleum Science and Engineering, 190(1), 1-16. https://doi.org/10.1016/j.petrol.2020.107015

Halim, I., Amir, R. A., Nashir, M., Syafri, I., Ilmi, N. N., \& Raharjo, W. B. (2017). A Comprehensive Geochemical Study Using Pyrolysis Analysis and Migration Pathway Map to Evaluate Source Rock Potential in Talang Akar Formation, Jambi SubBasin, South Sumatra, Indonesia. In AAPG Annual Convention and Exhibition (pp.1-17). Houstan, USA: AAPG Datapages Search and Discovery. https://www.searchanddiscovery.com/pdfz/docum ents/2017/10944halim/ndx_halim.pdf.html.

Hartwig, A., di Primio, R., Anka, Z., \& Horsfield, B. (2012). Source Rock Characteristics and Compositional Kinetic Models of Cretaceous Organic Rich Black Shales Offshore Southwestern Africa. Organic Geochemistry, 51(2), 17-34. https://doi.org/10.1016/j.orggeochem.2012.07.008

Heriyanto, N. (2018). An Overview of Hydrocarbon Maturity and Its Migration Aspects in Bunyu Island, Tarakan Basin. In Indonesian Petroleum Association Convention and Exhibition (pp. 1-22). Jakarta, Indonesia: AAPG Datapages Search and Discovery. https://doi.org/10.29118/ipa.1476.44562

Hidayati, S. (2018). Re-Visited Structural Framework of the Tarakan Sub-Basin Northeast Kalimantan Indonesia. In Indonesian Petroleum Convention and Exhibition (pp. 109-129). Jakarta, Indonesia: AAPG Datapages Search and Discovery. https://doi.org/10.29118/ipa.1717.07.g.109

Husein, S. (2017). Lithostratigraphy of Tabul Formation and Onshore Geology of Nunukan Island, North Kalimantan. Journal of Applied Geology, 2(1), 2535. https://doi.org/10.22146/jag.30255

Laksono, F.A.T., \& Manullang, S.F. (2020). Analisis Struktur Geologi Daerah Cinangsi Gandrungmangu Kabupaten Cilacap. Media Bina Ilmiah, 15(4), 4271-4278. https://doi.org/https://doi.org/10.33758/mbi.v15i4. 776

Laksono, F.A.T., Permanajati, I., \& Mualim, R. (2020). Analisis Kualitas Air di Lahan Reklamasi Pertambangan Nikel Desa Mohoni, Petasia Timur, Morowali Utara. Jurnal Sains Teknologi \& Lingkungan, $\quad 6(1), \quad$ 96-104. https://doi.org/10.29303/jstl.v6i1.142

Laksono, F.A.T., Ramadhan, G., Nurmajid, R.W., Paramita, L.A.G., \& Tsai, L.L.Y. (2020). Analisis Zona Resapan dan Keluaran Air Tanah di Desa Kutayu, Kabupaten Brebes. Dinamika Rekayasa, 16(2), 97-104. https://doi.org/10.20884/1.dr.2020.16.2.321

Laksono, F.A.T., Tsai, L.L.Y., \& Pilarczyk, J. (2021).
The Sedimentological Record of Upper Holocene Tsunami Event in Fengbin, Taiwan. Geopersia, 11(1), 169-203. https://doi.org/10.22059/geope.2020.301603.6485 48

Lentini, M. R. (2018). Aspects of the Neogene Tectonic History and Hydrocarbon Geology of the Tarakan Basin. In Indonesian Petroleum Association Convention and Exhibition (pp. 241-251). Jakarta, Indonesia: AAPG Datapages Search and Discovery. https://doi.org/10.29118/ipa.1757.241.251

Liu, D., Li, J., Liu, J. qi, \& Zhang, L. (2020). Modeling Hydrocarbon Accumulation Based on Gas Origin and Source Rock Distribution in Paleozoic Strata of the Ordos Basin, China. International Journal of Coal Geology, 225(1), 1-14. https://doi.org/10.1016/j.coal.2020.103486

Millayanti, A., Aprianto, A. R., Fauzan, R. F., \& Anggara, M. U. (2019). Evaluation of Organic Matters, Hydrocarbon Potential and Thermal Maturity of Source Rocks Based on Geochemical and Statistical Methods: Case Study Miocene of the Seblat and Lemau Formation, Bengkulu Basin. IOP Conference Series: Earth and Environmental Science $248 \quad 012075$. https://doi.org/10.1088/1755-1315/248/1/012075

Nainggolan, T. B., Manai, M. N. I., \& Subarsyah, S. (2018). Spectral Decomposition with Continuous Wavelet Transform for Hydrocarbon Zone Detection of North Bali Waters. Bulletin of the Marine Geology, 33(2), 79-92. https://doi.org/10.32693/bomg.33.2.2018.556

Nugroho, S. H., Putra, P. S., Yulianto, E., \& Noeradi, D. (2018). Multivariate Statistical Analysis for Characterization of Sedimentary Facies of Tarakan Sub-Basin, North Kalimantan. Marine Georesources and Geotechnology, 36(8), 907-917. https://doi.org/10.1080/1064119X.2017.1399178

Ogala, J. E., Kalaitzidis, S., Christanis, K., Omo-Irabor, O. O., Akinmosin, A., Yusuf, C. U., Pasadakis, N., Constantinopoulos, M., \& Papaefthymiou, H. (2019). Geochemical and Organic Petrological Study of Bituminous Sediments from Dahomey Basin, SW Nigeria. Marine and Petroleum Geology, 99(1), 577-595. https://doi.org/10.1016/j.marpetgeo.2018.10.033

Purnama, D. I., Putra, Y. S., Muhardi, M., Hayati, N., \& Triwerdhana, A. (2020). Identifikasi Potensi Batuan Induk pada Formasi Santul di SubCekungan Tarakan, Kalimantan Utara. Prisma Fisika, 8(1), 1-4. https://doi.org/10.26418/pf.v8i1.39637

Rahmola, W. R. P. (2018). The Organic Geochemistry of Oil Shale: Potential Source Rock of Galugur 


\section{TEKNIK, 42 (3), 2021, 271}

Unit in Kapur IX Intramontane Basin, West Sumatra. In Indonesian Petroleum Association Convention and Exhibition (pp. 227-247). Jakarta, Indonesia: AAPG Datapages Search and Discovery. https://doi.org/10.29118/ipa19.sg.227

Rizqi, A. H. F., \& Husein, S. (2017). Identifikasi Batuan Sumber Hidrokarbon Formasi Rambatan di Daerah Pamulihan, Kecamatan Larangan Kabupaten Brebes, Jawa Tengah. In Seminar Nasional Rekayasa Teknologi Industri dan Informasi (pp. 244-250). Yogyakarta, Indonesia: Institut Teknologi Nasional Yogyakarta. https://123dok.com/document/yn4o7pjzidentifikasi-hidrokarbon-formasi-rambatanpamulihan-kecamatan-larangan-kabupaten.html.

Ronoatmojo, I. S., \& Burhannudinnur, M. (2018). Anisotropic Properties Identification of Naintupo Formation, Tabul Formation and Tarakan Formation (Tarakan Sub-Basin) Using Anisotropic Parameters Determination Method from P-Wave Seismic Diffraction Function. IOP Conference Series: Earth and Environmental Science 212 012075. 1315/212/1/012075

Sha, J., Chen, J., Zhang, B., Chen, P., Zhang, S., Zeng, J., Liu, W., Wang, X., Zhang, P., Yao, D., Cao, J., \& Hu, Y. (2020). Geochemistry of Source RockControlled Late Triassic Coal: an Example from the Dabaoding Coal Mine in Panzhihua, Sichuan Province, Southwestern China. International Journal of Coal Geology, 221(1), 1-30. https://doi.org/10.1016/j.coal.2020.103431

Słowakiewicz, M., Gluyas, J., Kowalski, A., Edwards, T., Słama, S., Mawson, M., Tucker, M. E., Scovell, P., \& Polonio, I. (2020). A New and Working Petroleum Source Rock on the UK Continental Shelf (Upper Permian, Offshore Yorkshire). Marine and Petroleum Geology, 121(2), 1-18. https://doi.org/10.1016/j.marpetgeo.2020.104605

Sokol, E., Kozmenko, O., Smirnov, S., Sokol, I., Novikova, S., Tomilenko, A., Kokh, S., Ryazanova, T., Reutsky, V., Bul'bak, T., Vapnik, Y., \& Deyak, M. (2014). Geochemical Assessment of Hydrocarbon Migration Phenomena: Case Studies from the South-Western Margin of the Dead Sea Basin. Journal of Asian Earth Sciences, 93(2), 211-228. https://doi.org/10.1016/j.jseaes.2014.07.023

Spacapan, J. B., Palma, J. O., Galland, O., Manceda, R., Rocha, E., D’Odorico, A., \& Leanza, H. A. (2018). Thermal Impact of Igneous SillComplexes on Organic-Rich Formations and Implications for Petroleum Systems: a Case Study in the Northern Neuquén Basin, Argentina.
Marine and Petroleum Geology, 91(1), 519-531. https://doi.org/10.1016/j.marpetgeo.2018.01.018

Spigolon, A. L. D., Lewan, M. D., de Barros Penteado, H. L., Coutinho, L. F. C., \& Mendonça Filho, J. G. (2015). Evaluation of the Petroleum Composition and Quality with Increasing Thermal Maturity as Simulated by Hydrous Pyrolysis: a Case Study Using a Brazilian Source Rock with Type I Kerogen. Organic Geochemistry, 83(1), 27-53. https://doi.org/10.1016/j.orggeochem.2015.03.001

Subroto, E. A. (2018). Petroleum Geochemistry Study in a Sequence Stratigraphic Framework in the Simenggaris Block, Tarakan Basin, East Kalimantan, Indonesia. In Indonesian Petroleum Association Convention and Exhibition (pp. 421433). Jakarta, Indonesia: AAPG Datapages Search and https://doi.org/10.29118/ipa.673.05.g.159

Sukanta, U. (2018). Understanding HydrocarbonBearing Reservoirs and Their Critical Factors for Deep Water Exploration in the Tarakan Basin, North East Kalimantan, Indonesia. In Indonesian Petroleum Association Convention and Exhibition (pp. 155-175). Jakarta, Indonesia: AAPG Datapages Search and Discovery. https://doi.org/10.29118/ipa.2405.09.g.155

Walters, C. C. (2017). Origin of Petroleum. In Hsu, C.S. (Ed). Springer Handbook of Petroleum Technology (pp. 359-379). New York: Springer Publishing Company. https://doi.org/10.1007/9783-319-49347-3_10

Wang, G. C., Sun, M. Z., Gao, S. F., \& Tang, L. (2018). The Origin, Type and Hydrocarbon Generation Potential of Organic Matter in a MarineContinental Transitional Facies Shale Succession (Qaidam Basin, China). Scientific Reports, 8(1), 115. https://doi.org/10.1038/s41598-018-25051-1

Wang, P. C., Li, S. Z., Guo, L. L., Jiang, S. H., Somerville, I. D., Zhao, S. J., Zhu, B. D., Chen, J., Dai, L. M., Suo, Y. H., \& Han, B. (2016). Mesozoic and Cenozoic Accretionary Orogenic Processes in Borneo and Their Mechanisms. Geological Journal, 51(1), 464-489. https://doi.org/10.1002/gj.2835

Wicaksana, H.I., Laksono, F.A.T., \& Alam, A.R. (2018). The Problematical Solution of Shale Gas Explitation as Alternative Energy for National Independent Oil and Gas. In Indonesian Petroleum Association Convention and Exhibition (pp. 3038). Jakarta, Indonesia: AAPG Datapages Search and https://doi.org/10.29118/ipa.0.13.se.030

Widagdo, A., Purwasatriya, E.B., Laksono, F.A.T., \& Waluyo, S. (2021). Posisi Artefak Batuan pada Teras Sungai Klawing di Daerah Bobotsari, 


\section{TEKNIK, 42 (3), 2021, 272}

Kabupaten Purbalingga, Jawa Tengah. Media Bina Ilmiah, 15(7), 4861-4866. https://doi.org/10.33758/mbi.v15i7.953

Widjaja, P. H., \& Noeradi, D. (2016). 3D Properties Modeling to Support Reservoir Characteristics of W-ITB Field in Madura Strait Area. Bulletin of the Marine Geology, 25(2), 77-88. https://doi.org/10.32693/bomg.25.2.2010.27

Wijaya, P. H., Noeradi, D., Permadi, A. K., Usman, U., \& Djaja, A. W. (2012). Oil and Gas Potential on the Basis of Wells and Seismic Profiles Integration in Offshore Area of Tarakan Basin, East Kalimantan. Jurnal Geologi Kelautan, 10(3), 117132. http://dx.doi.org/10.32693/jgk.10.3.2012.221

Winegardner, D. L., \& Testa, S. M. (2020). Hydrocarbon Chemistry in Restoration of Contaminated Aquifers (p. 42). Boca Raton: CRC Press. https://doi.org/10.1201/9781420033014-6

Xiao, H., Li, M., Liu, J., Mao, F., Cheng, D., \& Yang, Z.
(2019). Oil-Oil and Oil-Source Rock Correlations in the Muglad Basin, Sudan and South Sudan: New Insights from Molecular Markers Analyses. Marine and Petroleum Geology, 103(1), 351-365. https://doi.org/10.1016/j.marpetgeo.2019.03.004

Xue, C., Wu, J., Zhong, J., Zhang, S., Zhang, B., Hao, B., \& Wang, D. (2019). Characteristics of the Marine-Terrigenous Interdepositional Shale: a Case Study of Taiyuan Formation in Linxing Area of Ordos Basin. Advances in Geo-Energy Research, 2(1), 72-85. https://doi.org/ 10.26804/ager.2018.01.07

Yang, Z., \& Zou, C. (2019). Exploring Petroleum Inside Source Kitchen: Connotation and Prospects of Source Rock Oil and Gas. Petroleum Exploration and Development, 46(1), 181-193. https://doi.org/10.1016/S1876-3804(19)30018-7 